\title{
ON THE EARLY THERMAL HISTORY OF CHONDRITIC ASTEROIDS DERIVED BY 244-PLUTONIUM FISSION TRACK THERMOMETRY
}

\author{
P. PELLAS and D. STORZER
}

Cooling curves were determined for ordinary chondrites within the time- and temperature intervals from $\sim 4.6$ to $\sim 4.1 \times 10^{9}$ years and $\sim 1400 \mathrm{~K}$ to $300 \mathrm{~K}$ respectively. This was done by analyzing the 244-plutonium fission track record in whitlockite and adjacent mineral track detectors. The resulting cooling rates constrain the sizes of the parent asteroids to $\sim 120-200 \mathrm{~km}$ in radius. These dimensions together with the fact that chondrites had never been molten, suggest

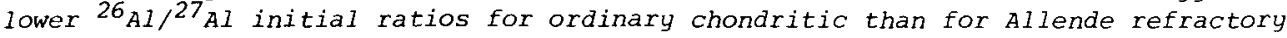
materials.

\section{INTRODUCTION}

The study of the early thermal history of meteoritic materials provides a key to the understanding of the initial conditions and subsequent evolution of their parent bodies. As shown by age determinations most materials crystallized about $4.6 \times 10^{9}$ years ago. There is general agreement that meteorites, whatever their type (irons, stones or stony-irons), experienced thermal effects to various extents during their early stages of evolution, when still embedded in their parent bodies. So far two methods have been applied to decipher the primary thermal history of meteorites. One, a metallographic method, is based on the study of nickel diffusion gradients in the $\mathrm{Fe}-\mathrm{Ni}$ phases of iron meteorites and metallic inclusions of chondrites. The other, a radiometric method, is based on the spontaneous fission of $244 \mathrm{Pu}$, using the fission tracks recorded in different mineral phases of stony meteorites.

\section{COOLING RATES RELATED TO THE Fe-Ni SYSTEM}

Iron meteorites are classified texturally into three main groups: octahedrites, ataxites and hexahedrites. The most common type are octahedrites which contain an internal structure called the Widmanstätten pattern. When polished sections are etched in dilute acid they show an octahedrically oriented array of kamacite plates (6-7\% Ni-alloy) coated with fine lame)lae of taenite (15-50\% $\mathrm{Ni}$. The Widmanstätten structure seems to have formed upon cooling of the iron 
from an initially liquid state. Its formation can be understood in terms of the $\mathrm{Fe}-\mathrm{Ni}$ phase diagram (see Wood 1964; Goldstein and Ogilvie 1965). In a cooling Fe-Ni alloy, containing e.g., $8 \%$ nickel, taenjte is the stable phase above $750^{\circ} \mathrm{C}$ Below this temperature kamacite starts to nucleate in the taenite and grows by solid state diffusion. As the temperature drops, the diffusion rate of nickel also decreases, causing compositional zoning near the taenitr-kamacjte interfaces Actual cooling rates are estimated by fitting theoretical gradients, simulated by crystal growth models, to the measured nickel composition gradients. The results, probably accurate within a factor of $2-3$, give an estimate of the rates at which the irons cooled through the temperature-range of about $700-500^{\circ} \mathrm{C}$ (Wood 1964; Goldstein and Ogilvie 1965; Goldstein and Short 1967a and 1967b; Goldstein and Doan 1972).

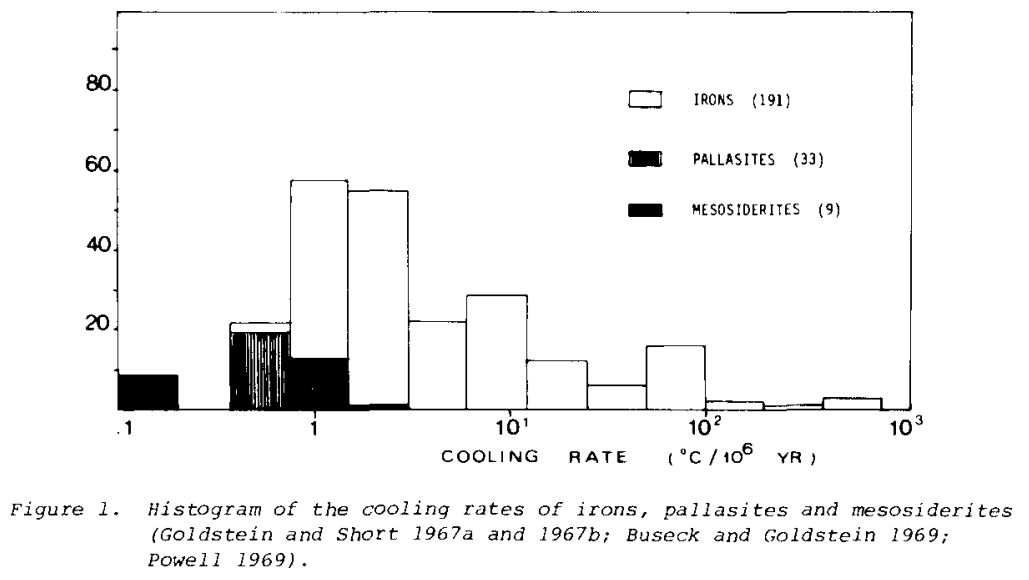

Cooling rates of irons, as well as pallasites and mesosjderjtes are shown in Figure 1. For irons these estimates range between $1-10^{\circ} \mathrm{C} / 10^{6}$ yr for two thirds of the meteorites studied but show a total variation between $0.4-500^{\circ} \mathrm{c/}$ $10^{6}$ yrs. From this it was suggested that the maximum size of the parent body (bodies) was about $300 \mathrm{~km}$ in radius, provided that the meteorites formed in the center (Goldstein and Short 1967b). Pallasites seem to have cooled more slowly than most iron meteorites, between $0.5-2.0^{\circ} \mathrm{C} / 10^{6} \mathrm{yr}$ (Buseck and Goldstein 1969), whereas mesosiderite cooling rates are the lowest yet determined for any meteorite $\sim 0.1^{\circ} \mathrm{C} / 10^{6}$ yr (Powe 11 1969).

Wood (1967) adapted the metallographic method also to ordinary and some carbonaceous chondrites, because taenite and kamacite grains show nickel distrjbution profiles just like those observed in octahedrites, despite their dispersion within the silicate phases. The well crystallized ordinary chondrites of petrologic types 5 and 6 seem to have cooled through $500^{\circ} \mathrm{C}$ with rates of $1-10^{\circ} \mathrm{C} / 10^{6} \mathrm{y}$ whereas type 3 carbonaceous and unequilibrated ordinary chondrites cooled with rates of $0.1-1^{\circ} \mathrm{C} / 10^{6} \mathrm{yrs}$. These estimates are rather contradictory due to the observation that the unequilibrated chondrites show the least textural and mineralogical evidence of thermo-chemical equilibration although they cooled most slowly through $500^{\circ} \mathrm{C}$ (Dodd 1969). Malezieux (1974) applied Wond's method to the ordinary chondrites Sena and Tillaberi and obtained cooling rates of $100 \mathrm{C} / 10^{6} \mathrm{yr}$ and $130^{\circ} \mathrm{C} / 10^{6}$ yr respectively. However, a comparison with the conling rates determined by the radiometric method for these two chondrites puts some doubts on the reliability of the metallographic method, at least when applied to chondrites. 


\section{CHONDRITIC ASTEROIDS}

\section{COOLING RATES OF ORDINARY CHONDRITES DERIVED BY THE 244-PLUTONIUM FISSION TRACK THER!IOMETRY}

Ordinary chondrites are the most abundant meteorites ( $78 \%$ of all known falls). On the basis of their bulk chemical composition, their oxydation state and free metal content they are divided into three groups: 1) the bronzite chondrites or H-group; 2) the hypersthene chondrites or L-group; 3) the amphoterites or LL-grour; . These three discrete chemical groups are subdivided into five petrologic types, sc. that type 3 , the least crystallized (unequilibrated), shows a texture highly chondritic, whereas type 7 , the most crystallized, shows a virtual absence of relict chondrule structure. Types 4,5 and 6 are intermediate types (Van Schmus and Wood 1967; Dodd et al. 1975). According to Van Schmus (1969) the approximate abundance of silicate minerals in type 6 chondrites are in wt\%: olivine (33-60), orthopyroxene (14-17), clinopyroxene (4-5), feldspar (9-10). Among the accessory minerals, phosphates are of special interest because of their enrichment in actinide elements by factors up to $10^{5}$ compared to pyroxene and olivine. The abundance of phosphates, however, does not exceed $0.5 \mathrm{wt} \%$. Two phosphates are found in petrologic types 4-7: chlorapatite $\mathrm{Ca}_{5}\left(\mathrm{PO}_{4}\right)_{3}(\mathrm{Cl})$ and whitlockite $\mathrm{B}-\mathrm{Ca}_{3}\left(\mathrm{PO}_{4}\right)_{2}$ which is much more frequent $(60-99 \%)$. Compared to apatite, whitlockite is enriched in ${ }^{244} \mathrm{Pu}$ whereas its U-content is lower. In whitlockites from the same chondrite the number of $244 \mathrm{Pu}$ fission tracks (hence, the former plutonium content) is strikingly constant; variations are mostly below $30 \%$ (Pellas and Storzer 1975a). Therefore, chondritic whitlockites are very promising for the application of the fission track method to chronometry and paleothermometry.

Here the fission track method is based on the spontaneous fission of the nearly extinct $244 \mathrm{pu}$ ard the $238 \mathrm{U}$ (see e.g., F1eischer et al. 1965). Fission fragments passing through insulating crystals as whitlockite, olivine, pyroxene. leave submicroscopic trails of radiation-damaged material, the latent tracks. These can be developed by selective chemical etching into a light-microscopically visible size. As the latent tracks accumulate within a given mineral in the course of time, their density (tracks $/ \mathrm{cm}^{2}$ ) is only a function of the plutonium and uranium contents and the time which has elapsed since the mineral was formed. The fraction of ${ }^{244} \mathrm{Pu}$ tracks is obtained by subtraction of the cosmic ray track and the $238 \mathrm{U}$ track background. In this study these corrections were mostly less than $15 \%$ of the total track density. This results from the selection of chondrites with on $1 y$ low cosmic ray exposure ages, the high fission probability of $244 \mathrm{pu}$ $\left(\lambda_{\mathrm{f}}=1.058 \times 10^{-11} \mathrm{yr}^{-1}\right)$ compared to that of $238_{\mathrm{U}}\left(\lambda_{\mathrm{f}}=8.46 \times 10^{-17} \mathrm{yr}^{-1}\right)$ and the high $244 \mathrm{Pu} / 238 \mathrm{U}$ ratio in whitlockite $(\sim 0.04$ in St. Séverin Ll6). The precise time, however, at which the plutonium fission tracks started to be recorded is not known. It only follows from the short half-life of ${ }^{244} \mathrm{Pu}\left(\tau / 1 / 2=8.18 \times 10^{7}\right.$ yr) that plutonium tracks date by necessity from the time-span $4.6^{2}$ to $3.7 \times 10^{9}$ years.

Another complication arises from the relatively low thermal stability of fission tracks. At elevated temperatures they start to fade. In whitlockites of St. Séverin, for example, the fission track excess attributed to $244 \mathrm{Pu}$ spontaneous fission (Cantelaube et al. 1967) does not correspond to the 244 pu fission xenon in this mineral. Ahout 25 times more xenon was found than expected from the track density (Wasserburg ot al. 1969; Lewis 1975). This discrepancy is explained by the high xenon retention temperature of whitlockite compared to its fission track retention temperature. During the early cooling history of St. Severin material xenon was, thcrefore, retained about $3.8 \times 10^{8}$ years prior to fission tracks. If we knew the xenon and track retention temperatures the data could be directly translated into a cooling rate. It is, indeed, possible to estimate these temperatures, starting from the fission track excess in whitlockite. The procedure is based on the observations: a) fission tracks change their size characteristically with the amount of thermal fading, b) the fission track 
retention temperatures are not identical among different minerals but increase in the sequence: whitlockite - olivine - orthopyroxene - clinopyroxene.

The stability of fission tracks is determined by laboratory annealing experiments, treat ing induced tracks at several temperatures over different periods of time. The results are then cxtrapolated to the lower temperatures which prevailed during geological times. Recent track fading investigations in a geological time-temperature system proved these extrapolations to be correct up to $10^{8}$ years (Naeser and Forbes 1976). Therefore, we know that a slowly cooling whitlockite at first does not retain fission tracks until it passes through a temperature range defined by $150 \pm 20^{\circ} \mathrm{C}$ and $30 \pm 10^{\circ} \mathrm{C}$. This range corresponds to track retention probabilities between $0 \%$ and $100 \%$. This is why increasingly more tracks survive. Below $30^{\circ} \mathrm{C}$ all newly formed tracks are completely preserved. Because of their distinctly smaller size distribution it is possible to discriminate tracks formed within the temperature domain 150-30 $\mathrm{C}$ from those formed below $30^{\circ} \mathrm{C}$. By means of a calibrated track length - track density relationship, the partially faded track population can then be corrected to a track density value corresponding to the full track length (Storzer 1970).

In order to extend the time - temperature sequence defined by the whitlockite, cxternal faces of other mineral detectors with higher track retention temperatures have been used. These detcctors, olivine and pyroxenes, in close contact with whitlockite crystals, registered and stored the fission fragments coming from the phosphates. However, in the case of olivine and pyroxenes which were irradiated in a 2 Il geometry it is experimentally difficult to separate the partially faded and the intact track populations. Here, after correction for a $4 \pi$ registration geometry, the total number of tracks recorded on the irradiated surfaces of these minerals corresponds approximately to the $50 \%$ track retention probability of the actual detector. The $50_{0}^{\circ}$ track retention temperatures, extrapolated from annealing experiments with fission tracks coming from a thick external source, are estimated to be: $200 \pm 30^{\circ} \mathrm{C}$ for olivine; $280 \pm 20^{\circ} \mathrm{C}$ for orthopyroxene (bronzito, hypersthene); and $350+40^{\circ} \mathrm{C}$ for clinopyroxene.

Finally, if the 244 pu fission xenon content of whitlockite is known it also can be translated into a fission track density. This number corresponds to the expected track density in case of an instantaneous cooling. From the St. Séverin whitlockite data the $50^{\circ}$ xenon retention temperature is extrapolated to $650^{\circ} \pm 60^{\circ} \mathrm{C}$.

The advantage of plutonium fission track analyses in whit lockite and adjacent fossil mineral track detectors is obviously twofold. As the fission tracks in the different detectors are only related to the 244 pu content in whit lockite as a common track source, differences in track density among minerals with increasing track retention temperatures are only a function of the fast plutonium decay. The differences of track density in the various minerals define precisely the times which elapsed until the tracks were retained in the actual detector. The mineral itself defines very sensitively the temperature at which the fission track clock started to operate. Thus, in the best case the thermal history of a chondrite can be retraced during the first few half-1ives of $244 \mathrm{pu}$ in the temperature interval between $650^{\circ} \mathrm{C}$ and $30^{\circ} \mathrm{C}$. Due to the extreme scarcity of cspecially whitlockite - olivine contacts this objective was not casily met. It should also be noted that the ahove temperature estimates were only derived cxperimentally for St. Séverin minerals and al low for slight differences among minerals from different chemical chondrite groups. In addition, there is preliminary experimertal evidence that the correction factors for a $4 \pi$ registration geometry are -2.7 and -2.4 for olivine and pyroxene respectively, rather than 2.0 as assumed in this paper. However, inevitable future modifications due to more refined calibrations are not considered to alter essentially the intepretation of our experimental data.

Although, for different chondrites the time - temperature sequences are on a floatimg time-scalc with respect to each other, they can be translated to a cooling rate for each individual metcorite. Alternatively with the assmotion 


\section{CHONDRITIC ASTEROIDS}

of an identical former plutonium content among all chondritic whitlockites the cooling curves plot on a fixed time-seale. This is shown in Figure 2 for the St. Severin and Shaw chondrites. Within the experimental uncertaintics the track data for St. Severin plot on a monotonically decreasing curve in the time vs. temperature frame. A similar behaviour is observed for the Shaw data. These two cooling curves can be approximated with the following expressions:

$$
\begin{aligned}
& T_{(K) S t . S e ́ v .}=053.5 \exp \left(-7.58 \times 10^{-9} \mathrm{t}\right)+269.5 \text { with } 270<\mathrm{T}<923 \\
& T_{(K) \text { Shaw }}=1102.3 \exp \left(-0.81 \times 10^{-9} \mathrm{t}\right)+270.7 \mathrm{with} 271<\mathrm{T}<1373
\end{aligned}
$$

where $t$ defines the time elapsed since the $50 \%$ retention probability of ${ }^{244} \mathrm{Pu}$ fission xenon was realized. The time $t_{0}$ is assumed to correspond to $4.50 \times 10^{9} \mathrm{yr}$ when ${ }^{40}$ Ar was retained (Alexander et al. 1972). The cooling rates $\left(K / 10^{6}\right.$ yr) for hoth chondrites are the following:

$$
\begin{aligned}
& \text { St. Séverin: } 920-5.50 k: 3.7+1.1 ; 550-300 k: 0.9+0.3 \\
& -0.8 ; \\
& \text { Shaw: } 1370-5.501:: 4.6+0.2 \\
& \quad+0.8 \text { (extrapolated); } 550-300 k: 0.8+0.2 .
\end{aligned}
$$

For the 12 chondrites studied similar cooling curves have been ohtained.

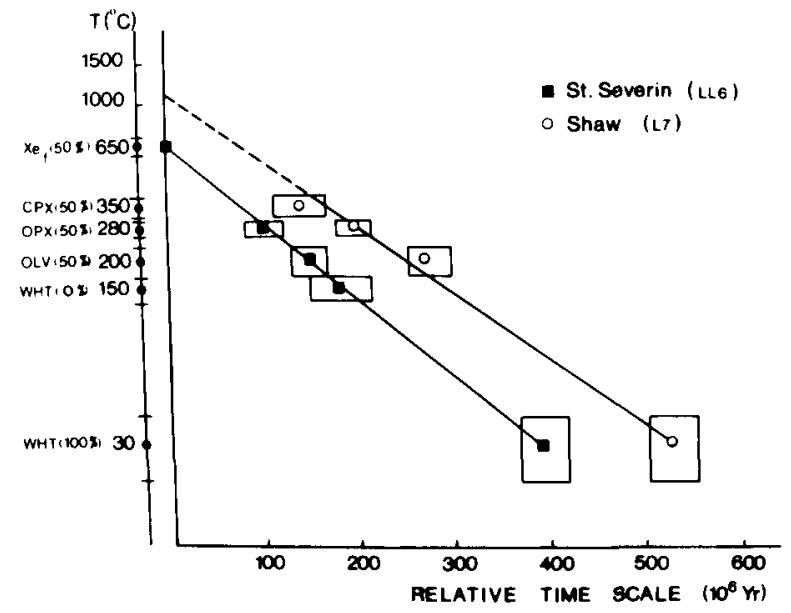

Figure 2. Cooling curves of St. Séverin (LLG) and Shaw (L7) chondrites. The St. séverin cooling curve was determined from the $244 \mathrm{pu}$ fission track excesses found in whitlockites, olivines and orthopyroxenes, and is extrapolated to time zero, corresponding to the fission xenon content of whitlockite. For the shaw cooling curve it was assumed that the 244 pu content of its whitlockites was identical with that of $S t$. séverin whitlockites (see text).

Nearly identical track data were found for chondrites helonging to the same petrologic type of a given chemical group. Figure 3 shows a compilation of these data relative to St. Severin. For the sake of clarity the uncertainties are not reported. In addition, some cooling curves are the average of several chondrites belonging to the same petrologic type and chemical group. In Table I the average cooling rates of the chondrites studied are compared with cooling rates obtained by the metallographic method. 


\section{PELLAS AND STORZER}

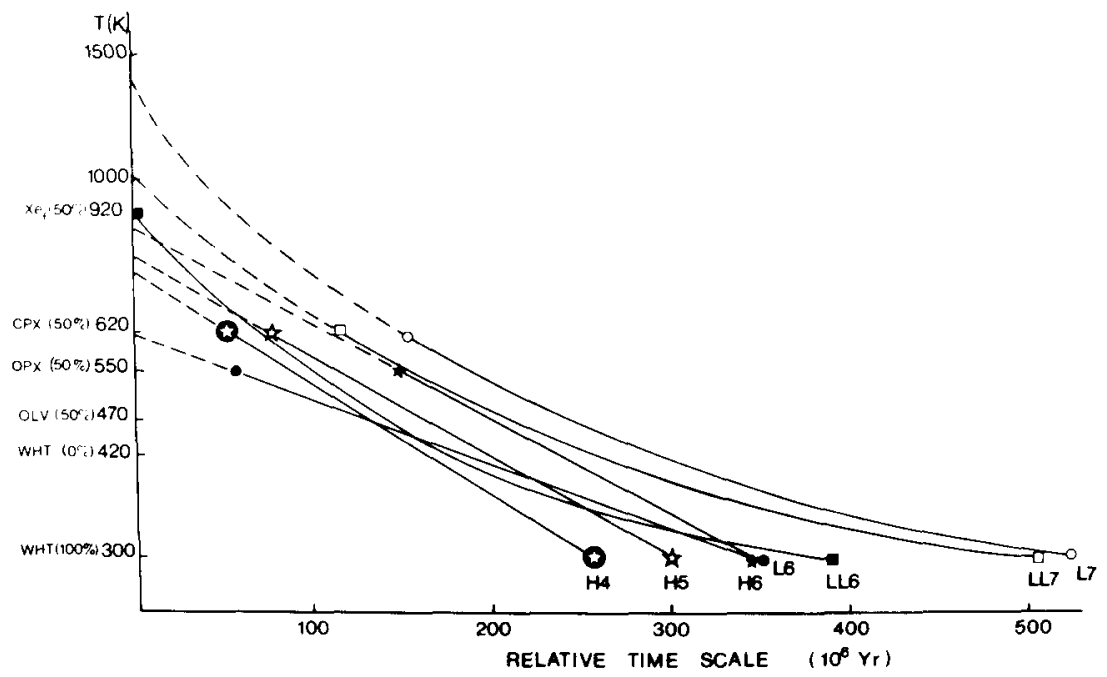

Figure 3. Cooling curves of ordinary chondritic materials. The curves are plotted assuming the same $P u$ content in whitlockites as in $S t$. Severin whitlockite. (Solid lines: experimental fission track cooling curves; dotted Iines: extrapolations to fission xenon retention time of $S t$. Séverin whitlockite). (Note that the code for $H 6$ is a black star, and EOI L6 a filled circle).

From the data in ligure 3 and Table I the following conclusions wan be drawn: a) Chondrites belonging to the sime chemical group and the same petrologi type show virtually the same cooling history; h) In cach chemical group the plutonium track densities in a given mineral phase decroas with incrasing mume

TABLE I

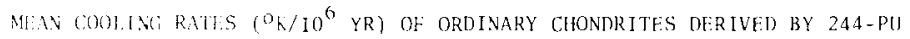

FISSION TRACK THLRMOME:TRY

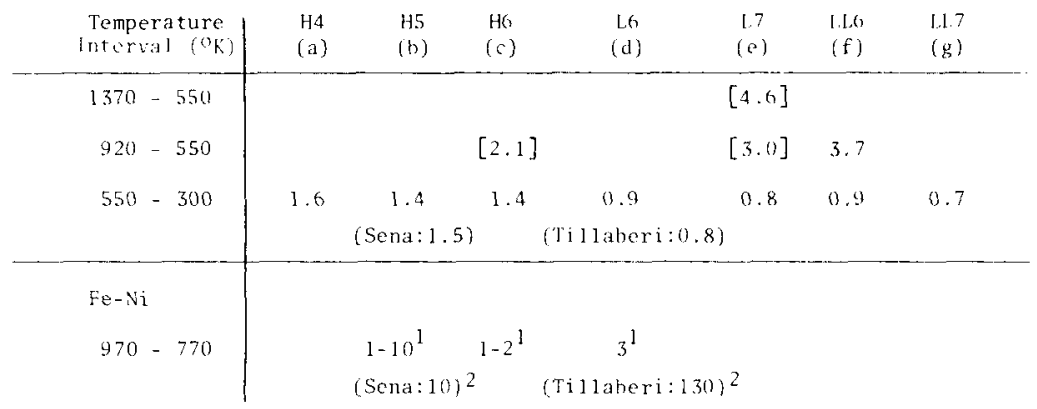

a: Beaver Creek, Kiffa; h: Sena, Allegan; c: Estacado, Guarena,

Kernouve; d: Peetz, Tillaberi; e: Shaw; f: St. Séverin; g: St. Mesmin (xenolith).

Between britchots: extrapolated values. I wood (1967); 2 Malezieux (1974). 
of petrologic type (H4-5-6, L6-7, LL6-7). Therefore, in each chemical group a definite relationship seems to exist between petrologic type and the time required for this material to arrive at a given temperature; the lower the number of petrologic type the earlier this temperature was reached. This is interpreted to reflect the thermal gradients inside the respective parent objects; c) On a fixed time-scale, relative to St. Séverin, there are large time differences for the various chondritic materials to cool down to a given temperature. For example, $550 \mathrm{~K}$ is reached in the sequence and accumulative time-lags $\left(10^{6} \mathrm{yr}\right.$ ) as follows: L6 - H4 ( 35) - LL6 $(\sim 45)-$ H5 $(\sim 60)-$ H6 $(\sim 90)-\operatorname{LL7}(\sim 100)-17(\sim 130)$. These time differences seem to be related to the dimensions of the parent bodies and the locations of the materials therein; d) If chondritic whitlockites had the same initial plutonium content, then the fission xenon in $H 6$ and LLG chondrites was retained at about the same time contrary to L6 materials which retained xenon earlier; e) Fission track cooling rates are mostly lower than metallographic estimates. For Tillaberi this discrepancy is very large $(0.8 \mathrm{vs}$. $\left.130^{\circ} / 10^{6} \mathrm{yr}\right)$; f) The good correlation between fission track cooling rates and petrologic types argues for the internal consistency of the method. In addition, the peak temperature $(\geq 1400 \mathrm{~K})$ estimated for Shaw (Figs. 2 and 3 ) agrees with the equilibration temperatures $(-1500-1600 \mathrm{~K})$ inferred for this chondrite from other thermometers (Fredriksson and Mason 1967; Dodd et al. 1975; Onuma et al. 19.72). This agreement indicates that fixing the time-scale of the cooling chondritic materials relative to $S t$. Séverin could be, indeed a realistic approach.

Thermal calculations on chondritic parent body models (Fricker et al. 1970); Herndon and Rowe 1973) and the fission track cooling rates constrain the dimensions of the parent asteroids. If material of petrologic types 6 or 7 was located in the center, the radii of the bodies would range from $\sim 120$ to $\sim 160 \mathrm{~km}$. A metallic core (with $R_{m} / R_{0}=0.5$ ) would increase the radii to $\sim 150-\sim 200 \mathrm{~km}$.

Accretion temperatures of ordinary chondrites, calculated from volatile trace element contents, converge on 450-500 K (Larimer 1973, and references therein). These temperatures imply that chondritic materials were reheated within a short time after accretion up to temperatures of at least $1400 \mathrm{~K}(\mathrm{e} . \mathrm{g}$., Shaw). Only then they cooled down monotonically as demonstrated by fission track thermometry. Pellas and Storzer (1975b) suggested that ordinary chondrites could result from almost simultaneous condensation and accretion processes during progressively decreasing temperatures $(\sim 1500-\sim 500 \mathrm{~K})$, because an efficient heat source was not known. This suggestion, however, conflicts with condensation path and trace element data (Grossman and Larimer 1974). With the discovery of in situ 26A1 decay in Allende refractory material (Lee et al. 1976; Papanastassiou, this volume) a very efficient heat source is provided to increase drastically the temperature of accreted materials within a short time-span. However, the high $26_{\mathrm{Al}} / 27_{\mathrm{Al}}$ ratio found $\left(6 \times 10^{-5}\right)$, implies that any chondritic body with a radius larger than 10 $\mathrm{km}$ would have been molten. As this is not observed in ordinary chondrites, and as their parent body radii exceed $100 \mathrm{~km}$, the ${ }^{26} \mathrm{Al} / 27_{\mathrm{A} 1}$ initial ratios of these materials should have been inferior to $10^{-5}$. This could be due either to isotopic inhomogenities in the nebula or to later accretion and formation times of ordinary chondritic bodies, when $26 \mathrm{Al}$ had already partially decayed.

\section{ACKNOWLEDGEMENTS}

Constructive remarks and helpful discussions with Drs. J. C. Lorin and A. E. Schoch are appreciated.

\section{REFERENCES}

Aijexander, E. C., Jr., Davis, P, K., and Lewis, R. S. 1972, Science, 175, 415. 


\section{PELLAS AND STORZER}

Buseck, P. R., and Goldstein, J. I. 1969, Bul1. Geol. Soc. Am. 80, 2141.

Cantelaube, Y., Maurette, M., and Pellas, P. 1967, in Radioactive Dating and Meth of Low-Level counting, (I.A.E.A. Vienna), p. 215.

Dodd, R. T. 1969, Geochim. Cosmochim. Acta, 3.3, 161 .

Dodd, R. T., Grover, J. E., and Brown, G. E. 1975, Geochim. Cosmochim, Rcta, 39, 1585 .

Fleischer, R. L., Price, P. B., and Walker, R. M. 1965, J. Geophys. Res. 70, 2703

Fricker, P. E., Goldstein, J. I., and Summers, A. L. 1970, Geochim. Cosmochim. Acta, 34, 475 .

Fredriksson, K., and Mason, B. 1967, Geochim. Cosmochim. Acta, 31, 1705.

Goldstein, J. I., and Doan, A. S., Jr. 1972, Geochim. Cosmochim. Acta, $36,51$.

Goldstein, J. I., and Ogilvie, R. E. 1965, Geochim. Cosmochim. Acta, $29,893$.

Goldstein, J. I., and Short, J. M. 1967a, Geochim. Cosmochim. Acta, 31, 1001.

Goldstein, J. I., and Short, J. M. 1967b, Geochim. Cosmochim. Acta, 31, 1733.

Grossman, L., and Larimer, J. W. 1974, Rev. Geophys. Space Phys. 12, 71.

Herndon, J. M., and Rowe, M. W. 1973, Nature, 244, 40.

Larimer, J. W. 1973, Geochim. Cosmochim. Acta, 37, 1603.

Lee, T., Papanastassiou, D. A., and Wasserburg, G. J. 1976. Geophys. Res. Letters. 3, 109 .

Lewis, R. S. 1975, Geochim. Cosmochim. Acta, 39, 417.

Malezieux, J. M. 1974, Thesis, Paris VI Iniversity.

Naeser, C. W., and Forbes, R. B. 1976, Eos, 57, 352.

Onuma, N., Clayton, R. N., and Mayeda, T. K. 1972, Geochim. Cosmochim. Acta, 36, 157 .

Pellas, P., and Storzer, D. 1975a, Meteoritics 10, 471.

Pellas, P., and Storzer, D. 1975b, C. R. ACad. SCi., 280 D, 225.

Powe11, B. N. 1969, Geochim. Cosmochim. Acta, 33, 789.

Storzer, D. 1970, Earth Planet. Sci. Lett., 8, 55.

Van Schmus, W. R. 1969, Earth Sci. Rev. 5, 145.

Van Schmus, W. R., and Wood, J. A. 1967, Geochim. Cosmochim. Acta, 31, 747.

Wasserburg, G. J., Huneke, J. C., and Burnett, D. S. 1969, J. Geophys. Res. 74, 4221 .

Wood, J. A. 1964, Icarus, 3, 429.

Wood, J.A. 1967, Icarus, 6, 1 .

\section{DISCUSSION}

WETHERILL: I don't understand your objection to ${ }^{26}$ Al as a heat source. Although the quantity of ${ }^{26} \mathrm{Al}$ found in one Allende sample would melt chondrites, there is no reason to suppose this is a representative sample of $26_{\mathrm{Al}}$ in the solar system, and somewhat less $26 \mathrm{Al}$ would agree with your results. The importance of the LeePapanastassiou result is not the exact quantity of $26_{A} 1$ found, but that the short half-life of ${ }^{26}$ Al can no longer be used as an argument against the importance of ${ }^{26} \mathrm{Al}$ as a heat source.

PELLAS. Perhaps you misunderstood my objection to ${ }^{26}$ Al as a heat source. ACtuall! there is no objection except the high $26_{\mathrm{Al}} / 27_{\mathrm{Al}}$ ratio. With a lower ratio at the time of the parent-body formations, the chondritic material would be heated but not melted. And that is exactly what we need to explain the observed cooling rates and the inferred parent-body sizes.

ANDERS: There is no contradiction between low accretion temperatures (450 $\mathrm{K})$ and high post-accretional temperatures. The parent bodies of differentiated meteorites (irons, achondrites) certainly got hot enough to melt after accretion, and so much have been heated by a powerful heat source (Al26, inductive heating, etc.) 


\section{CHONDRITIC ASTEROIDS}

Judging from the $S r$ isotopic composition of achondrites, this melting occurred very early within less than $10^{7}$ years after accretion. Thus, at least the large parent bodies started out warm, heated up and then cooled; they did not have the monotonic cooling history assumed by you. It stands to reason that smaller bodies wcre heated by the same heat source, but to lower peak temperatures.

PELLAS: I would like to precise that a monotonic cooling history is no longer assumed since the beginning of the accretion process. The monotonic cooling since the fission xenon retention in whitlockite is interpreted from the experimental data of pu fission track thermometry. If in the past I felt some disagreements about the low accretion temperatures estimated from volatile trace element contents in chondrites, I am quite ready to change my mind as a result of the $26_{A I}$ discovery. It could well explain a prior heating history before the start of fission track thermometers. In that sense your remark, already proposed two years ago, has proved to be well justifica.

WOOD: Your figure relating track densities to track retention temperatures showed substantial uncertainties related to each mineral. What uncertainties do these imply for the cooling rates you derive?

PELLAS: The uncertainties in the cooling rates are estimated to be $\pm 40 \%$. They result from two factors: 1. Scatter in the Pu-fission track densities among whitlockite crystals, and 2. uncertainties for the track-retention temperatures of the different mineral phases. 